\title{
Design de experiência ambiental hospitalar - foco no atendimento à criança.
}

Design de experiência ambiental hospitalar - foco no atendimento à criança.

PEREIRA, Aline Garcia; Mestra; Universidade Federal de Santa Catarina

aalinegp@gmail.com

MACHADO, Laís; Mestra; Universidade Federal de Santa Catarina

I.machado@posgrad.ufsc.edu.br

VERGARA, Lizandra Garcia Lupi Vergara; Doutora; Instituição de Ensino Superior

I.vergara@ufsc.br

\section{Resumo}

Este artigo apresenta os conceitos de Design de Experiência Ambiental, com foco no ambiente hospitalar voltado para o atendimento de crianças. O objetivo deste estudo, é descrever aspectos do Design de Experiência Ambiental, fatores ambientais e comportamentais que podem tornar a experiência do atendimento prazeroso ao público infantil. Esta é uma pesquisa bibliográficadocumental e por meio da revisão bibliográfica apresenta os conceitos e fatores pela perspectiva dos diferentes autores, com intuito de apresentar um panorama atual sobre o tema.

Palavras Chave: Experiência do Usuário; Experiência Ambiental para saúde; Design.

\begin{abstract}
This article presents the concepts of Environmental Design, focusing on the hospital environment focused on the care of children. The objective of this study is to describe aspects of Environmental Design, and environmental and behavioral factors that can make the experience of childcare enjoyable. This is a bibliographical-documentary research, and for the bibliographical media presents the concepts and the models from the perspective of the authors, in order to present a current panorama on the theme.
\end{abstract}

Keywords: User experience; Ambient experience design for healthcare; Design. 


\section{Introdução}

Após a segunda metade do século XX, no âmbito hospitalar, o avanço da tecnologia propiciou aos profissionais uma visão mais técnica do trabalho, com viés mecanicista. Isto acabou ocasionando a perda da empatia e acolhimento por alguns profissionais da área (MIRANDA, 2000).

A criança, diferente do adulto, possui sua própria maneira de ver o mundo, e no processo de socialização, evidencia-se a necessidade de tratar a criança na sua singularidade. Brougère (1984) diz que "toda socialização pressupõe apropriação da cultura, de uma cultura compartilhada por toda a sociedade ou parte dela". Para Vigostski (2006), o desenvolvimento da criança com o meio, se dá através das relações sociais, da criança com o mundo. Na perspectiva do atendimento hospitalar, é importante que o setor de radiologia (o qual é muitas vezes impessoal e desumano) facilite esse processo de socialização, sendo um ambiente que propicie o desenvolvimento da criança com o meio (ALVARES et al., 2006; LACERDA et al., 2008; SOUZA et al., 2013; WHO, 1983).

No ambiente hospitalar, a criança está sujeita a vários procedimentos invasivos, muitas vezes dolorosos (CUNHA; SILVA, 2013); um ambiente pouco iluminado (FERREIRA; REMEDI; LIMA, 2006); além de rotinas e práticas hospitalares muito diferentes da sua realidade cotidiana (FONTES, 2005); levando-a ao desconforto e estranhamento com o ambiente. Neste contexto, a problemática do presente estudo tem como pergunta: Como o design pode favorecer o atendimento do público infantil?

A escolha desta temática se deu em função de demandas de serviço como: humanização (SOUSA, 2007; BORBA, 2013; MARTENDAL, 2010), biossegurança (VIEIRA, 2010; MACHADO, 2011), proteção radiológica (FERREIRA, 2007; SOARES; PEREIRA; FLÔR, 2011), design do serviço e gestão (PEREIRA et al., 2015), Experiência do usuário - UX (GARRET, 2010) entre outros.

Para este fim, a presente pesquisa realiza um levantamento sobre os fatores envolvidos no conceito de design de experiência ambiental para a saúde (Ambient experience design for healthcare). Para Anastos (2007) o design de experiência ambiental se concentra no uso da luz, espaço e tecnologia, para criar maior conforto ao paciente, permite que o paciente personalize o ambiente para se adequar a seu humor ou personalidade. Assim, o autor propõe que o mesmo, tenha escolhas, e por meio do design de experiência ambiental venha melhorar a qualidade de vida (ANASTOS, 2007; ROGERS, SHARP e PREECE, 2013).

Assim, de acordo com que foi exposto, o presente estudo realiza um levantamento bibliográfico acerca dos fatores envolvidos no design de experiência ambiental para a saúde, com intuito de auxiliar o processo de compreensão dos fatores ambientais e comportamentais envolvidos, e seus impactos na experiência do atendimento infantil hospitalar.

\section{Procedimentos metodológicos}

\subsection{Caracterização da pesquisa}

O presente artigo é classificado como uma pesquisa bibliográfica-documental. Segundo seus objetivos, se classifica como exploratória, de modo a investigar por meio da literatura e propiciar maior familiaridade com o tema. Quanto aos procedimentos de coleta, se caracteriza como pesquisa bibliográfica, elaborada a partir de material já publicado em livros, revistas, artigos, dissertações, teses entre outros. Sobre sua abordagem, se classifica como qualitativa, à medida que se baseia em ideias teóricas e no conteúdo publicado. Quanto a natureza, se define como uma pesquisa básica, 
pois busca novos conhecimentos (LAKATOS e MARCONI, 2011).

\subsection{Etapas da pesquisa}

A pesquisa se divide em três etapas: (I) levantamento nas bases de dados (II) Levantamento em outras fontes e (II) Compreensão e análise. Na Etapa I realizou-se o levantamento dos conceitos acerca do tema, pela perspectiva de diferentes autores. Para isto, fez-se inicialmente uma apuração nas bases de dados Scielo e Scopus sobre Humanização e Design. Utilizou-se as palavras-chave com conectores booleanos: "Radiology AND (Humanization OR Humanizing) AND Design". Preliminarmente foram identificados respectivamente 13 artigos na Scielo e 54 artigos na Scopus, (fazendo o uso do filtro somente artigos). Em um segundo momento, iniciou-se a leitura dos títulos, identificou-se 19 artigos; depois da leitura do abstract, 5 artigos; e na última etapa de seleção, na procura do documento completo, (busca do pdf free) chegou-se a 3 artigos ligados ao tema em questão.

Na etapa II, foram investigados Trabalhos de Conclusões de Cursos, Dissertações, Teses, livros, sites de empresas, a fim de encontrar literaturas referentes aos temas: Design, Ambient Experience Design, Experience Design for Healthcare, Radiologia e Saúde. Na etapa III, se deu as leituras das bibliografias encontradas. Assim, realizou-se as análises e compreensão das relações entre os conceitos apresentados. As etapas I, II e III estão apresentadas na figura 1.

Figura 1 - Etapas da Pesquisa.

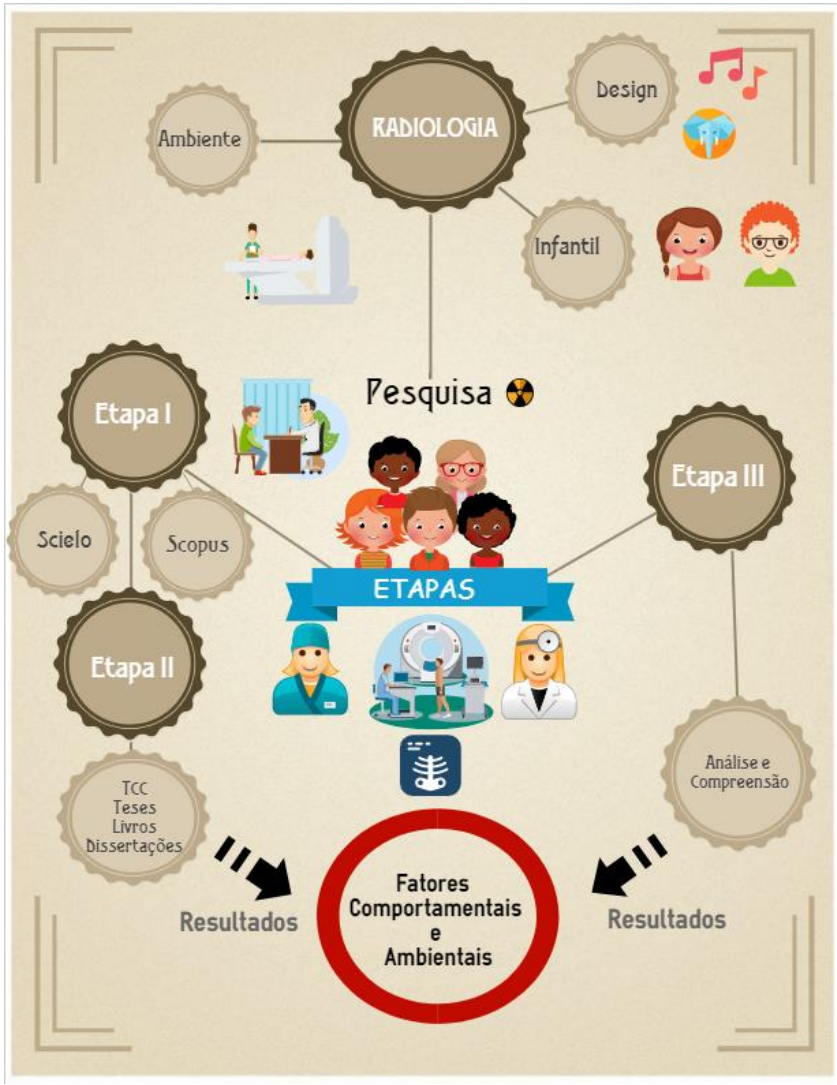

Fonte: Criado pelas autoras.

De maneira geral, foram selecionadas as bibliografias e documentos que convergiam com o objetivo da pesquisa. Organizou-se esses documentos entre os fatores comportamentais e 
ambientais envolvidos com Ambient Experience Design.

\section{Revisão de Literatura}

No presente tópico, são apresentados alguns conceitos relacionados ao tema central do presente estudo. Assuntos como experiência do usuário, design de experiência ambiental, fatores ambientais e comportamentais que afetam diretamente a experiência nos ambientes hospitalares e clínicas.

\subsection{O conceito de Experiência do usuário (UX)}

Segundo Norman (2006), a emoção é necessária para o homem, é inerente a vida, e esta que torna o homem inteligente. A emoção auxilia o processo de decisão, sobre um potencial perigo ou um potencial. Ainda segundo o autor, alguns produtos e objetos podem evocar emoções fortes e positivas como: amor, apego e felicidade. Já a experiência do usuário (UX) é uma consequência de diversos fatores, as emoções, preferências, percepções, estado físico e psicológico, habilidades e do contexto de uso (GARRET, 2010).

A experiência do usuário (UX) foi definida pelo ISO 9241-210 (2008) como sendo "as percepções de uma pessoa e as respostas que resultam do uso e/ou antecipado de um produto, sistema ou serviço". Para Garret (2010) a UX não é sobre o funcionamento interno de um produto ou serviço, porém sobre como ele funciona no exterior, onde uma pessoa entra em contato com ele. Quando alguém questiona como é usar um produto ou serviço, a pergunta é sobre a experiência do usuário deste objeto. Cada produto usado por alguém, cria uma experiência a este usuário: como livros, garrafas de ketchup, poltronas reclináveis, camisolas. (GARRET, 2010).

Há muitos aspectos da experiência do usuário que podem ser considerados, e existem diversas formas de fazê-lo (ROGERS, SHARP e PREECE, 2013). Um fator importante é a qualidade da experiência, seja ela rápida, como recarregar um telefone celular, vagarosa como jogar um brinquedo interativo, ou integrada como visitar um museu. (LAW et al, 2009).

Fica claro que a experiência não é algo apenas intrínseco de um produto, e sim de muitos fatores que envolvem a interação entre o homem e um objeto ou ambiente. Em resumo, a experiência do usuário pode estar aplicada a um produto, um sistema, serviço ou mesmo no ambiente. Em vista disso, identifica-se que o design pode auxiliar no processo de experiência do atendimento hospitalar.

\subsection{Aspectos do Design de experiência Ambiental para saúde}

Para Martendal (2010) o atendimento a crianças deve ser diferenciado, devido a maior sensibilidade que possuem. No mesmo sentido, o autor apresenta que existem diferentes formas de tornar um serviço hospitalar mais humanizado, dentre eles: musicoterapia, literatura, recreações, atividades lúdicas, incentivo da presença dos familiares, incentivo ao contato com outras crianças, incentivo relacional com os funcionários, além do respeito a individualidade e subjetividade do indivíduo (MARTENDAL, 2010).

As últimas duas décadas foram marcadas por ambientes hospitalares que afetam o usuário de maneira passiva, com pouca interação e muitas vezes promovendo uma experiência negativa. $O$ design de experiência ambiental por outro lado, reconhece que o conforto ambiental pode ser muito diferente de um paciente para o outro, assim permite a autonomia do paciente sobre alguns elementos do ambiente, como a iluminação, som, de forma a reduzir a ansiedade e estresse 
(ANASTOS, 2007).

Na pesquisa de Anastos (2007) sobre radiologia, o autor apresenta os resultados positivos na experiência do atendimento infantil, com a aplicação do design de experiência ambiental. 0 autor destaca que o ambiente composto de animações coloridas para as crianças e natureza como árvores, plantas e outros elementos, despertavam a tranquilidade. "No Ambient Experience for healthcare foi permitido que o paciente escolhesse elementos como iluminação, som que deixasse o paciente confortável, o que reduziu a sensação de ansiedade e estresse nos cuidados com a saúde" (ANASTOS, 2007).

Outro exemplo de design de experiência ambiental, aplicado a exames de radiologia em crianças, ocorreu no Lutheran General Children's Hospital and Royal Philips Electronics (PHI) localizado em Illinois, nos Estados Unidos. Este ambiente desenvolvido por uma equipe de engenheiros, designers, psicólogos, pediatras e arquitetos, possui uma preocupação com o bemestar e experiência da criança, na realização dos exames de radiologia. Todo o ambiente (desde a sala de espera, até a realização do exame) foram pensados para proporcionar uma boa experiência para a criança, diminuindo estresse e uso de sedativos nestes pacientes.

\subsection{Fatores envolvidos no Design de experiência ambiental}

O presente estudo apresenta os conceitos que podem auxiliar no desenvolvimento do ambiente hospitalar mais humanizado para crianças, divididos em dois fatores: Fatores Ambientais e os Fatores Comportamentais, conforme Figura 2.

Figura 2 - Fatores Ambientais e Comportamentais.

\section{FATORES}

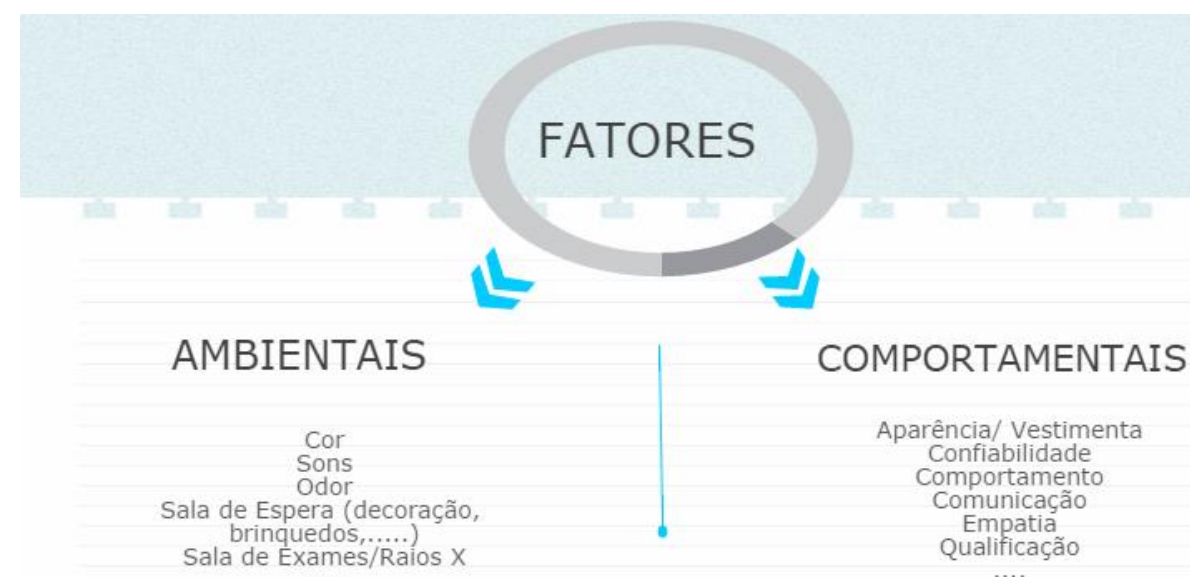

Fonte: Criado pelo autor

\subsubsection{Fatores Ambientais}

Para o presente estudo, tem-se como fatores ambientais todos os critérios relacionados ao ambiente que podem influenciar a emoções e sensações da experiência de atendimento. Dessa forma, os fatores ambientais referem-se aqueles que compõe o ambiente nas questões estéticas e sensoriais como: cores, sons, odores, e outras relações com a sala de espera e a sala de raios $\mathrm{X}$.

Um dos fatores ambientais são as cores. Elas exercem grande influência nas sensações humanas, podem tornar o ambiente mais animado, mais agradável, o que influencia nas atitudes e percepções das pessoas no local (BOCCANERA; BOCCANERA; BARBOSA, 2006). 
Assim como tudo na natureza, nas cores também existem as polaridades, como cores frias e quentes. O vermelho e suas variações são consideradas como cores quentes, e os tons de azul considerados frios. Na área da saúde, as cores devem ser adequadas ao ambiente hospitalar, transmitir sensações de bem-estar, tranquilidade aos pacientes, sejam eles adultos, idosos ou crianças (BOCCANERA; BOCCANERA; BARBOSA, 2006; ANDREWS; WELLS; OLIVEIRA, 1989).

Lacy, afirma que atualmente nos hospitais, há a necessidade de mudanças para alegrar os ambientes (LACY, 2000). Sobre as sensações das cores no ambiente hospitalar, Boccanera, Boccanera e Barbosa (2006) realizam uma pesquisa com 39 pessoas (sendo 29 profissionais e 10 clientes), afim de compreender as preferências de cores neste tipo de ambiente. Os resultados identificaram as cores azul claro, verde claro e branco (26\% dos profissionais e $29 \%$ dos pacientes, o branco por $23 \%$ e $29 \%$, o verde claro $20 \%$ e $14 \%$ ) como sendo as cores mais agradáveis para este tipo de ambiente.

Em contrapartida, Lacy (2000) destaca que o uso excessivo de cores frias pode causar um efeito ruim, (como o uso de azul claro por exemplo) em locais como a recepção de hospitais. 0 autor relata que por um lado, estas cores são calmantes, porém podem ter um efeito contrário nestes ambientes hospitalares, no qual as pessoas precisam sentir-se emocionalmente amparadas. A recepção deve ser receptiva, o autor reforça que, quando se usa uma tonalidade clara de vermelho ou laranja como cor predominante, é possível criar um ambiente relaxante para o paciente e aconchegante para o visitante (LACY, 2000).

Nesta perspectiva, os tons pálidos de cinza, assim como o branco e o creme, juntos com uma cor vibrante, realçam estas cores, sendo eficazes no ambiente hospitalar ${ }^{1}$. 0 autor ressalta que o turquesa é uma cor ideal para hospitais e outros estabelecimentos de saúde, pois contém azul e verde, assim, quando utilizado como cor predominante no ambiente, pode acalmar o sistema nervoso e relaxar o paciente de forma natural, promovendo um efeito calmante nas emoções. 0 complemento do turquesa deve ser feito com cores complementares, que mantenham o equilíbrio entre cores quentes e frias. (LACY, 2000).

Além das diferentes cores do ambiente, a decoração, como o uso de figuras, imagens, podem auxiliar a redução do medo das crianças. Um exemplo de aplicação, que se pode destacar, é o Hospital Presbiteriano Morgan Stanley de Nova York, que modificou o ambiente de tomografia com imagens nas paredes, chão, adaptação de todo equipamento com a temática de Piratas (ver Figura 3).

Figura 3 - Ambiente com uso de imagens temáticas

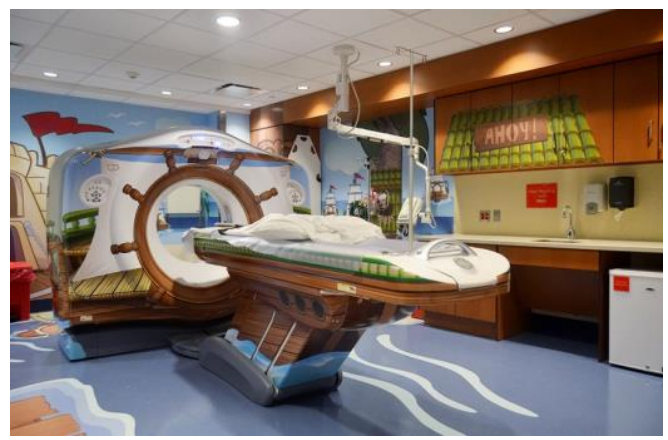

Fonte: Pirate CT Scanner at Morgan Stanley Children's Hospital - Pinterest ${ }^{1}$.

\footnotetext{
${ }^{1}$ Disponível em: https://br.pinterest.com/pin/61994932343791998/
} 
Conforme as pesquisas apresentadas, observa-se que a cor do ambiente hospitalar é uma ferramenta valiosa na criação de um ambiente mais adequado as necessidades do paciente infantil e mais humanizado de um modo geral.

Outro fator que pode auxiliar em uma boa experiência no ambiente hospitalar são os sons. Assim como a fala, a escrita e a linguagem corporal, a música também é uma forma de interação com as pessoas e o ambiente ao seu redor. A criança, desde os primeiros anos de vida está cercada de intensos estímulos sonoros. Estudos apresentam a influência da música no desenvolvimento da criança. Em alguns casos a relação estabelecida na infância com uma determinada melodia pode perdurar por toda a vida (SANTOS, 2005).

Também se faz uso da música e dos sons para fins terapêuticos, esse recurso é chamado de musicoterapia. A musicoterapia foi tomada por alguns pesquisadores como um valioso recurso terapêutico, devido as sensações que a música pode provocar no ser humano. A musicoterapia é uma disciplina que auxilia a medicina, se preocupa com a investigação do som e o ser humano, na busca por métodos de diagnóstico dos efeitos terapêuticos no homem (ZAMPRONHA, 1985; SANTOS, 2005; PICADO; EL-KHOURI; STREAPCO, 2007).

Alguns estudos realizados, apontaram que a música pode diminuir a ansiedade e tensão em crianças hospitalizadas. Além disso, há evidências do auxílio da música na diminuição do estresse e menor sensibilidade à dor (PICADO, 2007). Este método, é uma forma barata e acessível de melhorar a qualidade do sono, diminuição da dor, do medo e da tristeza em crianças hospitalizadas (FERRREIRA; REMEDI; LIMA, 2006).

Os sons, tanto quanto a música, podem ser uma ótima ferramenta de redução do estresse, no atendido radiológico, tanto em crianças como adultos; podendo reduzir a ansiedade e acalmar, e tornar a experiência do cuidado com a saúde mais agradável (WALWORTH, 2010).

O olfato, é outro fator que pode influenciar nas experiências vivenciadas. O sentido do olfato possui grande importância em um mundo onde quase tudo tem cheiro, porém não se valoriza muito este sentido. Os odores possuem relação próxima com as memórias, também com caráter afetivo e terapêutico como humor, depressão, euforia, irritação ou sedução (WOSNY, 2001). Está ligado diretamente ao comportamento humano, gerando reações inconscientes como a calma, irritabilidade, medo, coragem entre outros (SCHWAB, 2003).

Para Wosny (2001), os odores no geral podem indicar múltiplos significados. As experiências olfativas mediam o primeiro contato do homem com o mundo, por meio do cheiro materno e também de outras relações ligadas ao instinto de sobrevivência. Assim inicia-se o processo de conhecimento do homem, que segue adquirindo mais e mais experiências olfativas, suas características, estímulos e outras relações com o cheiro.

Em decorrência de algumas legislações ligadas ao ambiente hospitalar, se faz uso de produtos químicos e sépticos, que acabam deixando no ambiente odores característicos. Porém, estes cheiros característicos aos hospitais e outros centros de saúde, acabam despertando relações, muitas vezes negativas ao paciente (WOSNY, 2001).

Já o design de experiência ambiental busca substituir estes aromas por outros que tragam sensações de conforto e calma. Desta forma, o cuidado com os aromas no ambiente hospitalar pode proporcionar ambientes mais aconchegantes ao público infantil, diminuindo a necessidade de medicamentos para acalmá-las. 
O processo de socialização está ligado a apropriação da cultura, assim, para que haja apropriação, a criança se utiliza de diferentes elementos como: confrontação com imagens, com representações, com formas diversas. Sob a mesma perspectiva, é imprescindível ressaltar a importância dos jogos, brincadeiras, que trabalhem o lúdico da criança, e assim, impulsione seu desenvolvimento de comunicação e socialização (BROUGÈRE, 1994).

Neste sentido, é importante que o setor tenha uma sala de espera apropriada para o público infantil, que além de ser um ambiente alegre, deve ter uma boa decoração, e artigos para o público, como brinquedos e desenhos. Martendal (2010) ressalta a preocupação supracitada, bem como a disposição do espaço, pode ajudar a minimizar a ansiedade do paciente. Hoje, mais que um benefício e um serviço, o que se entrega ao cliente é a experiência.

Dentre os fatores do ambiente, deve-se enfatizar que as vestimentas são parte integrante da experiência, assim como equipamentos e acessórios. Dentre os acessórios que um serviço deve possuir estão as Vestimentas de Proteção Radiológica (VPR), conhecidas também como Equipamentos de Proteção Individual (EPI). É importante que nos procedimentos, os acessórios necessários estejam sempre presentes. Além disso, os equipamentos de Radiologia devem estar em boas condições de uso, e ter uma manutenção preventiva (COUTO et al., 2003).

Ainda sobre a radiologia pediátrica, em um estudo apresenta do por Martendal (2010), o autor relatou que em nenhum procedimento observado foi fornecido VPR para a criança, ou para seu acompanhante, embora o setor tivesse os aventais, luvas plumbíferas, protetor de gônadas e tireoide. Em outros seis serviços avaliados, os equipamentos e procedimentos são precários, acarretando em maior exposição dos pacientes, dose até 40 vezes maior que o estabelecido (MARTENDAL, 2010; NAVARRO; COSTA; DREXLER, 2010). Para Fernandes, Carvalho e Azevedo, é interessante que o serviço forneça, quando necessário, VPR adequadas para crianças, considerando que VPR comum pesa cerca de 3,5 kg (FERNANDES; CARVALHO; AZEVEDO, 2005).

González (2015) relata que a probabilidade de ocorrência dos efeitos estocásticos é proporcional à dose, torna-se necessário atenção especial a radiologia pediátrica. Segundo estudos que o autor apresentou no Congresso de Proteção Radiológica, destaca-se a preocupação com os parâmetros de proteção radiológica das crianças, bem como necessidade de maiores estudos nessa área, pois existem questionamentos quanto aos valores de dose padrão "se as restrições atuais de dose são para crianças, eles são muito cautelosos para adultos. Se eles são para adultos são imprudentes para crianças" (GONZÁLEZ, 2015).

Outro estudo sobre o tema, realizado no Hospital Infantil Pequeno Príncipe em Curitiba, coletou-se características antropométricas do público infantil, bem como medidas de dose em tomografia e parâmetros de radiação dos exames. O objetivo foi, comparar os dados de dose com os protocolos internacionais e atribuir cálculo de risco. Dentre os resultados obtidos, observou-se que os valores de recém-nascidos estão acima do nível de referência, além da necessidade de otimizar a dose em pacientes neonatais, os quais recebem doses elevadas. (SCHELIN et al., 2015)

\subsubsection{Fatores Comportamentais}

Além dos fatores ambientais, outros fatores podem influenciar a experiência do atendimento hospitalar, são os fatores comportamentais. Estes, são ligados ao atendimento, vestimenta e aparência dos médicos, enfermeiros, entre outros profissionais e procedimentos.

Em um estudo realizado em 2013 no Brasil, (YONEKURA et al., 2013) investigou-se a 
impressão transmitida por diferentes estilos de vestimenta e aparência (vestimenta, acessórios, corte de cabelo e barba e atitudes) e a relação de confiabilidade e satisfação transmitida pelos médicos para os pacientes. $\mathrm{O}$ autor, conseguiu verificar quais as aparências mais satisfatórias para estes pacientes. Como resultado do estudo, o autor destaca a vestimenta inteiramente branca, como a indicada com maior frequência para profissionais de ambos os sexos, indicado como sinal de higiene pelos pacientes.

Ainda sobre o estudo de Yonekura et al. (2013), os dados sugerem que além da aparência ser um fator de grande relevância para a satisfação do paciente, as atitudes e comportamentos do profissional também são importantes para a satisfação e sensação de segurança do paciente.

$\mathrm{Na}$ interação do profissional com a criança, bem como seus acompanhantes, é muito importante que a comunicação seja clara e precisa, que haja respeito com ambos durante todo o procedimento. Apesar de se saber da importância de uma boa comunicação, nem todo exame é esclarecido; em muitos exames "normalmente vai se posicionando a criança e falando como ela deverá permanecer ou como o acompanhante deverá segurá-la no decorrer do posicionamento, isso se torna uma questão importante, pois a criança pode se sentir invadida se não existir um 'aviso' do que vai acontecer" (MARTENDAL, 2010).

Na pesquisa de Rawson et al (2016), relata-se aprendizados das últimas duas décadas em relação ao desenvolvimento de uma cultura centrada no paciente e na família, num serviço de radiologia. Dentre eles, estão: a utilização de brincadeiras para o aprendizado das crianças; ouvir o paciente é importante para modificar a cultura da instituição; um setor de radiologia pode ser um ambiente de cura; diferentes pacientes possuem expectativas diferentes sobre o mesmo espaço e experiência; ouvir as necessidades dos pacientes durante a realização do exame, pode resultar em maior satisfação e melhores resultados; os aventais disponibilizados para o paciente devem proteger a privacidade do mesmo.

Martendal (2010) relata que um fator que deve ser destacado, é quanto a privacidade do paciente. Assim, é importante garantir que durante os procedimentos e exames, as portas devem estar fechadas. No estudo realizado pelo autor, verificou uma deficiência quanto a privacidade nos atendimentos.

Além disso, é muito importante que hajam programas de reciclagens institucionais, a fim de aprimorar o desenvolvimento das competências profissionais (PEREIRA; VERGARA, 2015). Na pesquisa de Martendal (2010), os profissionais ressaltaram que não há iniciativa do hospital infantil, no que se refere a palestras, informações, e cursos de humanização. Para que a humanização se torne eficaz, é de suma importância ouvir as sugestões, queixas, angústias, pontos positivos das pessoas que estão ligadas diretamente ao processo.

\section{Discussão e Conclusão}

O presente artigo apresentou os fatores envolvidos no design de experiência ambiental para hospitais. Neste sentido, realizou-se um levantamento bibliográfico acerca do tema, e por meio da apresentação de conceitos, estudos e constatações, foi possível ter um entendimento de como o design pode auxiliar os cuidados com a saúde do público infantil.

Por meio da literatura, documentos apresentados, observou-se que a humanização hospitalar é possível por meio da união dos fatores ambientais e comportamentais. A cor do ambiente, a música, o odor, a configuração da sala de espera e sala de exames, podem contribuir 
para minimizar a ansiedade das crianças submetidas aos exames radiológicos. Além do ambiente físico e seus acessórios, é importante que o profissional das técnicas radiológicas esteja sempre se capacitando e tenha uma boa comunicação com a criança, bem como com os acompanhantes, afim de transmitir tranquilidade e as informações corretas para otimizar o exame.

Quanto as cores, destaca-se que os ambientes de saúde atualmente usam de forma excessiva cores frias, com intuito de tranquilizar a acalmar os pacientes. Porém, por meio do presente estudo, foi possível identificar que é viável trazer cores quentes como laranja, vermelho (em tonalidades mais claras); ou turquesa, neste ambiente de cuidado com a saúde, e ao mesmo tempo potencializar os efeitos de conforto e bem-estar.

A seleção adequada de imagens, personagens, cores, odores, sons do ambiente e músicas, podem auxiliar na redução da ansiedade dos pacientes, durante procedimentos e exames, e garantir que a experiência do atendimento hospitalar seja agradável as crianças. Outros fatores que influenciam diretamente na experiência, são os fatores comportamentais. A forma de atendimento, vestimentas dos médicos e enfermeiros, o modo de comunicação, entre outros, fazem parte da experiência do atendimento.

Este estudo, voltado ao ambiente hospitalar de atendimento infantil, mostra-se relevante, no sentido que a aplicação do design de experiência ambiental pode evitar traumas, frustrações, medos, ansiedades, e em contrapartida incentivar a prevenção, impulsionando a criança a querer cuidar da saúde ao tornar esse processo agradável e prazeroso.

Para estudos futuros, destaca-se assuntos como os limites de doses voltados para o público infantil; valores antropométricos para fabricação das vestimentas de proteção radiológica para as crianças; influência dos aspectos ambientais em setores públicos e privados de atendimento infantil; percepção das crianças frente a um setor humanizado e com design diferenciado.

\section{Referências}

ALVARES, B. R. et al. Achados normais no exame radiológico de tórax do recém-nascido. Radiol Bras. São Paulo, v; 39, n. 6, p. 435-440, 2006.

ANASTOS, John P. The ambient experience in pediatric radiology. Journal of Radiology Nursing, $\mathrm{V}$. 26, n. 2, p. 50-55, 2007.

\section{AMBIENT EXPERIENCE RADIOLOGY. Ambient Experience radiology suite opens at Illinois} children's hospital. Science Letter, 1319. Available from http://go.galegroup.com.ez46.periodicos.capes.gov.br/ps/i.do?id=GALE\%7CA267906772\&v=2.1\& $u=$ capes \&it $=r \& p=A O N E \& s w=w \& a s i d=12097 c 15661 e 419 e 2 b f 3 e a 89 b 013 c e 89$.

ANASTOS, J. P. The ambient experience in pediatric radiology. Journal of Radiology Nursing, v. 26, n. 2, p. 50-55, 2007.

ANDREWS, T.; WELLS, C.; OLIVEIRA, S. M. M. A cura pela cor. São Paulo: Estampa; 1989. BOCCANERA, N. B.; BOCCANERA, S. F. B; BARBOSA, M. A. As cores no ambiente de terapia intensiva: percepções de pacientes e profissionais. Rev. Esc. Enferm. USP. v. 40, n. 3, p. 343-9, 2006.

BORBA. A. K. A humanização da assistência em ambientes hospitalares: uma revisão integrativa. 
[Trabalho de Conclusão de Curso] Instituto Federal de Educação, Ciência e Tecnologia de Santa Catarina, 2013, 59 p.

BROUGÈRE, G. Brinquedo e cultura. 8th ed. São Paulo: Cortez; 1994.

CHIZZOTTI, A. Pesquisa em Ciências Humanas e Sociais. Cortez; 1995.

COUTO, N. F.et al. Modelo de gerenciamento da manutenção de equipamentos de radiologia convencional. Radiologia Brasileira, v. 36, n. 6, p. 353-361, 2003.

CUNHA, G. L.; SILVA, L. F. Lúdico como recurso para o cuidado de enfermagem pediátrica na punção venosa. Rev Rene [Internet]. 2013, v. 13, n. 5., p. 1056-65, 2013.

DEMO, P. Metodologia do conhecimento científico. Atlas; 2000.

FERNANDES, G. S.; CARVALHO, A. C. P.; AZEVEDO, A. C. P. Avaliação dos riscos ocupacionais de trabalhadores de serviços de radiologia. Radiol Bras. v. 38, n. 4, p. 279-281, 2005.

FERREIRA, C. A. A proteção radiológica na uti neonatal em um hospital público de Florianópolis. [Trabalho de Conclusão de Curso] CEFET, 2007, 68 p.

FERREIRA, C. C. M; REMEDI, P. P.; LIMA, R. A. G. A música como recurso no cuidado à criança hospitalizada: uma intervenção possível. Rev Bras Enferm.v. 59, n. 5, p. 689-93, 2006.

FONTES, R. S. A escuta pedagógica à criança hospitalizada: discutindo o papel da educação no hospital. Revista Brasileira de Educação, v. 29, n. 2., p. 119-139, 2005.

GARRETT, Jesse James. Elements of user experience, the: user-centered design for the web and beyond. Pearson Education, 2010.

GONZÁLEZ, A. J. Un desafío recurrente: La protección radiológica de cigotos, embriones, fetos, bebes, niños y adolescentes. Proceedings of $X$ Congreso Regional Latinoamericano IRPA de Protección y Seguridad Radiológica. Buenos Aires, 12-17 abril de 2015. Available from: http://www.irpabuenosaires2015.org/Archivos/archivos/Disertaciones\%20Especiales/2GONZALEZ\%20ABEL.pdf.

ISO/IEC. 2001. ISO 9241-11: Ergonomic requirements for office work with visual display terminals (VDTs) - pt.11: guindance on usability. Geneva: ISO, 1998. IV,22p.

HECKERT, A. L. C.; PASSOS, E.; BARROS, M. E. B. Um seminário dispositivo: a humanização do Sistema Único de Saúde (SUS) em debate. Interface - Comunicação, Saúde, Educação, Botucatu, v. 13, n. 1, p. 493-502, 2009.

LACERDA, M. A. de $S$. et al . Riscos dos exames radiográficos em recém-nascidos internados em um hospital público de Belo Horizonte, MG. Radiol Bras, São Paulo , v. 41, n. 5, p. 325-

329, Oct. 2008.

LACY, M. L. O poder das cores no equilíbrio dos ambientes. 2000. São Paulo: Pensamento. Brazil. LAKATOS, Eva Maria; MARCONI, Marina de Andrade. Metodologia do trabalho científico. 70 Ed Atlas SA. São Paulo p43-44, 2011.

Law, E. L. C., Roto, V., Hassenzahl, M., Vermeeren, A. P., \& Kort, J. (2009, April). Understanding, scoping and defining user experience: a survey approach. In Proceedings of the SIGCHI Conference on Human Factors in Computing Systems (pp. 719-728). ACM. 
MACHADO, W. J. Analisando a contaminação bacteriológica e aspectos de higienização em equipamentos de radiologia convencional. [Trabalho de Conclusão de Curso] Instituto Federal de Educação, Ciência e Tecnologia de Santa Catarina, Florianópolis, 2011, 51 p.

MARTENDAL, V. O processo de humanização no setor de radiologia convencional de um hospital infantil. [Trabalho de Conclusão de Curso] Instituto Federal de Educação, Ciência e Tecnologia de Santa Catarina, Florianópolis, 2010.

MIRANDA, J. M. Tecnologia, autonomia e dignidade humana na área da saúde. In: Siqueira JE, Prota L, Zancanaro L, organizadores. Bioética: estudos e reflexões. Londrina (PR): UEL; p.101-16, 2000.

NAVARRO, M. V. T.; COSTA, E. A.; DREXLER, G. G. Controle de riscos em radiodiagnóstico: uma abordagem de vigilância sanitária. Ciênc. saúde coletiva. v. 15, supl. 3, p. 3477-3486, 2010.

New York Presbyterian kids. Morgan Stanley Children's Hospital. Visitado em: 03 de Abril de 2018. Disponível em: http://www.nyp.org/morganstanley

NORMAN, Donald A. Emotional design: Why we love (or hate) everyday things. Basic books, 2004. ROGERS, Yvone; SHARP, Helen; PREECE, Jeniffer. Design de interação: além da interação humanocomputador. 3. ed. Porto Alegre: Bookman, 2013. 9 p.

PEREIRA, A. G.; VERGARA, L. G. L. Ensino das novas tecnologias e proteção radiológica para profissionais da saúde. Proceedings of the $X$ Congreso Regional Latinoamericano IRPA de Protección y Seguridad Radiológica. Buenos Aires, 12-17 abril de 2015. Available from: http://www.rivanet.com.ar/clientes/irpa/1_IRPA_2015_paper1_Aline_Lizandra.pdf PEREIRA et al. Soluções no serviço de radiologia no âmbito da gestão: uma revisão da literatura. Radiol Bras. São Paulo, v. 48, n. 5, p. 298-304, 2015.

PICADO, S. B. R.; EL-KHOURI, R. N; STREAPCO, P. T. Humanização hospitalar infantil e: intervenções musicoterapêuticas no Centro Clínica Electra Bonini. Revista Pediatria., v. 2, n. 29, p. 99-108, 2007.

PIRATE-THEMED CT SCANNER At NYC Hospital Helps Kids Get Over Fear Of Doctor Visits. New York Presbiteryan Morgan Stanley. Available from: http://www.medicaldaily.com/pirate-themed-ctscanner-nyc-hospital-helps-kids-get-over-fear-doctor-visits-254309 .

RAWSON, James $\mathrm{V}$. et al. Lessons learned from two decades of patient-and family-centered care in radiology, part 2: building a culture. Journal of the American College of Radiology, v. 13, n. 12, p. 1560-1565, 2016.

RIOS, I. C. Humanização: a essência da ação técnica e ética nas práticas de saúde. Rev. bras. educ. med. v. 33, n. 2, p. 253-261, 2009.

SANTOS, M. A. S. M. D. A música e a criança na educação infantil [Dissertação]. Universidade Candido Mendes, Rio de Janeiro; 2005.

SCHELIN, H. R. et al.. Assessment of organ dose in pediatric patients undergoing ct exam. Proceedings of the $X$ Congreso Regional Latinoamericano IRPA de Protección y Seguridad Radiológica. Buenos Aires, 12-17 abril de 2015. Available from: http://www.irpabuenosaires2015.org/?page_id=992. 
SCHWAB, F. C. C. Odores incômodos em emissões industriais: aspectos teóricos, práticas atuais e um estudo de caso em fábrica agroquímica [Dissertação]. Universidade do Estado do Rio de Janeiro, Rio de Janeiro; 2003.

SOARES, F.A.P.; PEREIRA A. G.; FLOR, R.C. Utilização de vestimentas de proteção radiológica para redução de dose absorvida: uma revisão integrativa da literatura. Radiol Bras. São Paulo, v.44, n. 2, p. 97-103, 2011.

SOUSA, N. R. Humanização no processo de trabalho dos profissionais das técnicas radiológicas em raios $x$ convencional: interação e acolhimento como dispositivos de reorganização profissional. [Trabalho de Conclusão de Curso]. CEFET, 2007, 74 p.

SOUZA, R. M. de et al. Uso da radiografia de tórax na unidade de tratamento intensivo pediátrico. Scientia Medica, v. 23, n. 3, 2013.

VIEIRA, G. C. Risco biológico ocasionado por doenças respiratórias em exames do trato respiratório em radiologia convencional no setor de diagnóstico por imagem. [Trabalho de Conclusão de Curso] Instituto Federal de Educação, Ciência e Tecnologia de Santa Catarina, Florianópolis, 2010, $57 \mathrm{p}$.

VIGOTSKI, LS. A formação social da mente. Editora Martins Fonte; 2006.

WALWORTH, D. D. Effect of live music therapy for patients undergoing magnetic resonance imaging. J Music Ther. v. 47, n. 4,p. 335-50, 2010.

WHO SCIENTIFIC GROUP et al. A rational approach to radiodiagnostic investigations. Indications for and Limitations of Major X-ray Diagnostic Investigations, p. 11-28, 1983.

WOSNY, A. D. M. Estética dos odores: o sentido do olfato no cuidado de enfermagem hospitalar. [Tese]. Doutorado em Enfermagem, Universidade Federal de Santa Catarina; Centro de Ciências da Saúde; 2001, $144 \mathrm{f}$.

YONEKURA, C. L. et al. Impressões de pacientes, médicos e estudantes de Medicina quanto a aparência dos médicos. Revista da Associação Médica Brasileira, v. 59, n. 5, p. 452-459, 2013.

ZAMPRONHA, M. L. S. Da música como recurso terapêutico. São Paulo: UNESP, Instituto de Artes do Planalto, 1985. 